\title{
The entransy dissipation minimization principle under given heat duty and heat transfer area conditions
}

\author{
GUO JiangFeng, XU MingTian* \& CHENG Lin \\ Institute of Thermal Science and Technology, Shandong University, Jinan 250061, China
}

Received February 7, 2010; accepted August 25, 2010; published online December 2, 2010

\begin{abstract}
Under given heat duty and heat transfer area conditions, the equipartition of the entransy dissipation (EoED) principle, the equipartition of the temperature difference (EoTD) principle, and the equipartition of the heat flux (EoHF) principle are applied to the optimization design of a heat exchanger with a variable heat transfer coefficient. The results show that the difference between the results obtained using the EoED and EoTD principles is very small, far smaller than that between the results obtained using the EoED and EoHF principles. The correct entransy dissipation minimization principle is chosen to optimize the parameters in the hot and cold fluids in a two-fluid heat exchanger, under given heat duty and heat transfer area conditions. The results indicate that the proper choice of the two alternative fluids has an important role in the successful application of the entransy dissipation minimization principle. The fluid that could improve the total heat transfer coefficient should be chosen, or the fluid that makes the temperature profiles of the hot and cold fluids parallel and decreases the temperature difference between the hot and cold fluids after optimization simultaneously, could be the proper one.
\end{abstract}

entransy dissipation, heat exchanger, equipartition of entransy dissipation, equipartition of temperature difference, equipartition of heat flux

Citation: Guo J F, Xu M T, Cheng L. The entransy dissipation minimization principle under given heat duty and heat transfer area conditions. Chinese Sci Bull, 2011, 56: 2071-2076, doi: 10.1007/s11434-010-4189-x

With the rapidly increasing price of petroleum and coal, the efficient use of energy resources has become one of the most effective ways of reducing demand on those resources. The heat exchanger as an energy utilization device is widely used in power engineering, petroleum refineries, and chemical and food industries. Hence, reducing unnecessary energy dissipation in a heat exchanger to improve its performance is an important goal. The heat transfer occurring in the heat exchange process usually involves heat conduction under a finite temperature difference, and with fluid friction and mixing. These are the typical irreversible non-equilibrium thermodynamic processes. In recent decades, the application of the second law of thermodynamics in heat exchangers has attracted a lot of attention [1]. Based on the principle of entropy production minimization advanced by Prigogine

*Corresponding author (email: mingtian@sdu.edu.cn)
[2], Bejan [3,4] developed the entropy generation minimization (EGM) approach to heat exchanger optimization design. Tondeur and Kvaalen [5] found that total entropy production reaches the minimum when the local rate of entropy production is uniformly distributed along the space and/or time variables in a contacting or separation device involving a given transfer area and achieving a specified transfer duty. This principle is called the equipartition of entropy production (EoEP). Sauar et al. [6] showed that the best trade-off between the energy dissipation and transfer area is achieved when the thermodynamic driving forces are uniformly distributed over the heat transfer area, which is called the equipartition of forces (EoF). Balkan [7] revealed that entropy production calculated with EoEP is always smaller than that calculated with EoF although the difference is considerably small in itself. Guo et al. [8] showed that a more uniform distribution of temperature difference 
along the counter flow heat exchanger, contributes to a better performance of the counter flow heat exchanger, compared with the parallel flow type. A new approach, the equipartition of temperature difference, EoTD, was proposed as a short-cut for minimizing entropy production by Balkan [7]. However, the entropy production minimization method also causes some inconsistencies and paradoxes [9-11]. Guo et al. [12] pointed out that the focus of entropy production minimization was on the heat-work conversion process, while the rate and efficiency of heat transfer related more to heat exchanger designs. Inspired by the analogy between heat and electrical conduction, Guo et al. $[12,13]$ defined a new physical quantity, entransy, to describe heat transfer ability. It was found that the entransy is dissipated in irreversible heat conduction processes; the more the dissipation of entransy the higher the degree of irreversibility [14]. Xu et al. [15] derived an expression for the local entransy dissipation rate for heat convection. Liu et al. [16] showed that the extremum principle of entransy dissipation is advantageous over the extremum principle of entropy generation when the heat exchanger is only for heating and cooling, while the latter is better than the former when the heat exchanger works in the Brayton cycle.

Guo et al. [13] indicated that when the volume-average thermal conductivity is kept constant, the temperature gradient in the domain should be uniform to minimize the entransy dissipation. Song et al. [17] used the extremum principle of entransy dissipation to optimize one-dimensional heat exchangers, and proved the validity of the uniformity principle of the temperature difference field in the heat exchangers. Xia et al. [18] stated further that the heat flux density is uniformly distributed along the heat exchanger when entransy dissipation reaches the minimum for fixed heat duty and Newton's law of the heat transfer process with a constant heat transfer coefficient. Meanwhile, the temperature difference between the hot and cold fluids is uniform along the heat exchanger, which is called the principle of equipartition of heat flux (EoHF) in this paper. Guo et al. [19] pointed out that the entransy dissipation rate reaches the minimum for a given heat duty and heat transfer area when the local entransy dissipation rate is uniformly distributed along the heat exchanger, no matter whether the heat transfer coefficient is constant or variable, which is called the principle of equipartition of entransy dissipation (EoED). They found that the EoED principle has better performance than the EoTD principle when heat transfer coefficient is variable.

Considering the above, under fixed heat duty and heat transfer area conditions, there are three principles to minimize entransy dissipation: the EoTD, EoHF and EoED principles. When the heat transfer coefficient is constant, these three principles are equivalent [19]. However, the reality is that the heat transfer coefficient is variable in heat exchangers. Thus the study of the performances of the three principles is of important practical significance when the heat transfer coefficient is variable. In addition, in the optimization of the two-fluid heat exchanger with a fixed heat duty and heat transfer area, the aim is often achieved by changing the parameters of one fluid while fixing the parameters of the other. However, the problem of which of the two alternative fluids should be chosen to minimize the entransy dissipation has not been discussed in existing literature. In this paper, when the heat transfer coefficient is variable, the optimization results obtained using the three principles are compared with each other, and the appropriate principle is selected to optimize the parameters in the hot and cold fluid sides of a two-fluid heat exchanger. Finally, the rules for choosing the proper fluid between the two alternatives are presented.

\section{Comparing the EoED, EoTD and EoHF prin- ciples}

For a simple heat exchange process as shown in Figure 1, a thin metal plate separates the hot and cold fluids. Assume both fluids are perfectly mixed in the $y$-direction. The length of the heat exchanger is $l$, heat is conducted only in the $x$-direction, and the bulk temperatures of both fluids vary only in the $z$-direction. Guo et al. [19] stated that the condition for minimum entransy dissipation occurs when the local entransy dissipation is uniform along the $z$-direction, i.e. the EoED principle. Assume $l=100 \mathrm{~m}$, the lengths in the

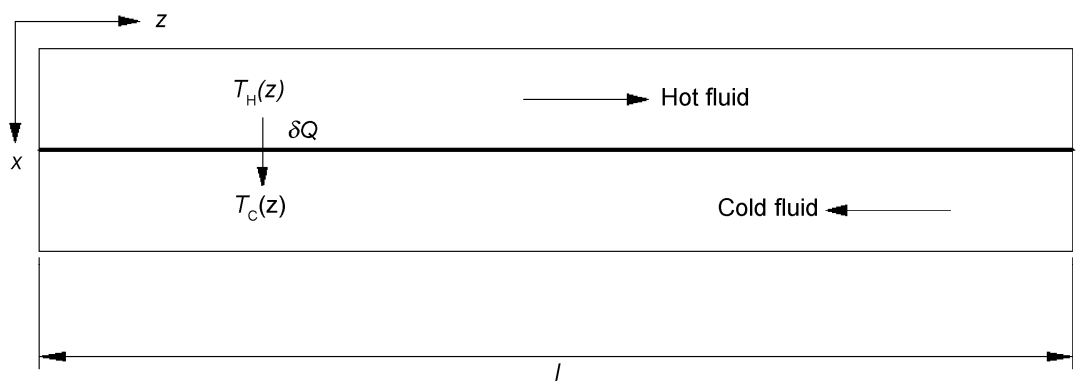

Figure 1 A simple heat exchanger. 
$x$-direction and $y$-direction are $\Delta x=1 \mathrm{~m}$ and $\Delta y=0.1 \mathrm{~m}$. Water is selected as the working fluid, and its thermophysical properties, such as density, thermal conductivity and viscosity, are expressed as cubic functions of temperature in order to eliminate the effect of fixed thermophysical properties on the results,

$$
\phi=a_{1}+a_{2} T+a_{3} T^{2}+a_{4} T^{3},
$$

where $\alpha_{1-4}$ are constants. The mass flow rate of the hot fluid is $\dot{m}_{\mathrm{h}}=2 \mathrm{~kg} / \mathrm{s}$, and the outlet temperature of the hot fluid is $T_{\mathrm{h}, \mathrm{o}}=320 \mathrm{~K}$. Because the mass flow rate and the outlet temperature of the hot fluid are given, when the inlet temperature of the hot fluid is given, the heat duty is fixed. According to the Dittus-Boelter correlation, the heat transfer coefficient is written as

$$
K=\frac{0.023 k_{\mathrm{f}}}{d}\left(\frac{v d}{\eta}\right)^{0.8} \operatorname{Pr}^{0.4},
$$

where $k_{\mathrm{f}}$ is the thermal conductivity of fluid, $d$ the equivalent diameter, $v$ velocity, $\eta$ the viscosity of the fluid, and $\mathrm{Pr}$ the Prandtl number. Because thermophysical properties are functions of temperature, when the velocity of the fluid and the equivalent diameter are given, the heat transfer coefficient is a function of temperature. The thermal resistance $R$ can be regarded as the reciprocal of the heat transfer coefficient $K$.

According to the principle of equipartition of entransy dissipation (EoED), the expressions of temperature gradient of hot fluid, heat flux density, local entransy dissipation rate and temperature of cold fluid in the heat exchanger can be deduced as [19]:

$$
\begin{aligned}
& \frac{\mathrm{d} T_{\mathrm{h}}}{\mathrm{d} z}=-\frac{\sqrt{-\Delta y C_{1}}}{\dot{m}_{\mathrm{h}} c_{\mathrm{ph}} \sqrt{R}}, \\
& q=\frac{\sqrt{-\Delta y C_{1}}}{\Delta y \sqrt{R}}, e=-\frac{C_{1}}{\Delta x \Delta y}, \\
& T_{\mathrm{c}}=T_{\mathrm{h}}-\frac{\sqrt{-\Delta y C_{1} R}}{\Delta y},
\end{aligned}
$$

where $C_{1}$ is constant, subscripts $\mathrm{h}$ and c denote hot and cold fluid, and $c_{\mathrm{p}}$ is the specific heat. The $C_{1}$ can be solved by the Euler method and the Newton iteration method when inlet and outlet temperatures of the hot fluid are given. Accordingly, the temperature of the hot fluid, heat flux density, local entransy dissipation rate and temperature of the cold fluid in the heat exchanger can be determined.

According to the principle of equipartition of temperature difference (EoTD), when the temperature difference between the hot and cold fluids is uniform in the heat exchanger, the expressions for the temperature gradient of the hot fluid, heat flux density, local entransy dissipation rate and temperature of the cold fluid in the heat exchanger can be deduced as [19]:

$$
\frac{\mathrm{d} T_{\mathrm{h}}}{\mathrm{d} z}=-\frac{\Delta y C_{2}}{\dot{m}_{\mathrm{h}} c_{\mathrm{ph}}}, e=\frac{R C_{2}^{2}}{\Delta x}, T_{\mathrm{c}}=T_{\mathrm{h}}-R C_{2},
$$

where $C_{2}$ is constant and can be solved by the Euler method and the Newton iteration method when the inlet and outlet temperatures of the hot fluid are given. Accordingly, the temperature of the hot fluid, local entransy dissipation rate and temperature of the cold fluid in the heat exchanger can be determined.

For the sake of comparison, the entransy dissipation number is adopted in the present work, and can be written as [20]:

$$
E^{*}=\frac{\dot{E}_{\mathrm{diss}}}{Q\left(T_{\mathrm{h}, \mathrm{i}}-T_{\mathrm{c}, \mathrm{i}}\right)},
$$

where $Q$ is the total heat transfer rate, $T_{\mathrm{h}, \mathrm{i}}$ and $T_{\mathrm{c}, \mathrm{i}}$ are the inlet temperatures of the hot and cold fluids, and $\dot{E}_{\text {diss }}$ is the total entransy dissipation rate. The entransy dissipation number represents the ratio of actual entransy dissipation to maximum entransy dissipation in the heat exchanger. The lower the entransy dissipation number, the better the heat transfer process, and the two extreme cases 0 and 1 denote that the entransy dissipation rate is zero and at the maximum. Assuming the inlet temperature of the hot fluid is $T_{\mathrm{h}, \mathrm{i}}=370 \mathrm{~K}$, then the local entransy dissipation rates obtained according to the three principles in the heat exchanger, are demonstrated in Figure 2.

As shown in Figure 2, the local entransy dissipation rate obtained using the EoED principle remains the same in the heat exchanger. In the part of $z<50 \mathrm{~m}$, the local entransy dissipation rate obtained using the EoTD principle is larger than that obtained using the EoED principle, while the local entransy dissipation rate obtained using the EoTD principle is less than that obtained using the EoED principle in the later stage. However, the local entransy dissipation rate obtained using the EoHF principle is always larger than the rates obtained using the EoED and EoTD principles, and diminishes as $z$ grows.

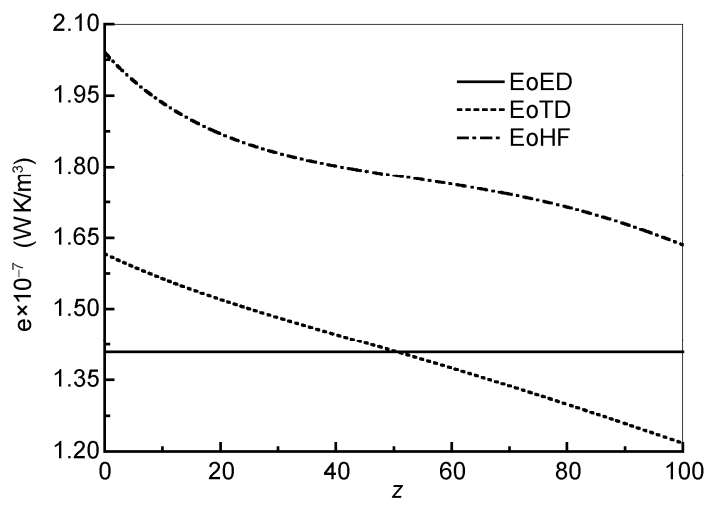

Figure 2 Distribution of local entransy dissipation rate in the heat exchanger. 
When $T_{\mathrm{h}, \mathrm{i}}=370 \mathrm{~K}$, the optimization results obtained with the three principles are documented in Table 1. As Table 1 shows, the total entransy dissipation rate obtained using the EoED principle is the lowest, followed by the total entransy dissipation rate obtained using the EoTD principle, while the total entransy dissipation rate obtained using the EoHF principle is the largest. Compared with the total entransy dissipation rate obtained using the EoTD principle, the total entransy dissipation rate obtained using the EoED principle is reduced by only $0.15 \%$, while the total entransy dissipation rate obtained using the EoED principle is reduced by $27.4 \%$ compared with that obtained using the EoHF principle. Compared with the EoHF principle, the EoTD principle approximates to the EoED principle. Table 1 shows that the mass flow rate of cold fluid obtained using the EoHF principle is the largest, followed by that obtained using the EoTD principle, while the mass flow rate of the cold fluid obtained using the EoED principle is the smallest. This indicates that when the local entransy dissipation rate is uniform in the heat exchanger, the heat exchanger has the highest thermal efficiency under the given heat duty and area conditions, which can be illustrated by the heat exchanger effectivenesses obtained using the three principles. The effectiveness obtained using the EoED principle is the largest, the effectiveness obtained using the EoTD principle comes next, followed by that obtained using the EoHF principle. As shown in Table 1, the sequence of the entransy dissipation numbers obtained using the three principles is the opposite to the order of the effectivenesses obtained using the three principles. The entransy dissipation number obtained using the EoED principle is the smallest, followed by the entransy dissipation number obtained using the EoTD principle, while the entransy dissipation number obtained using the EoHF principle is the largest.

\section{Application of the optimization principle to two-fluid heat exchangers}

In a practical two-fluid heat exchanger, the optimization is often conducted by changing the parameters of one fluid and fixing the condition of the other fluid. Balkan [21] presented the guidelines for choosing the proper fluid between the two alternatives to be modified, which would minimize the entropy production. This paper discusses the rules for choosing the proper fluid between the two alternatives to

Table 1 Comparison between the optimization results obtained using the three principles $\left(T_{\mathrm{h}, \mathrm{i}}=370 \mathrm{~K}\right)$

\begin{tabular}{cccc}
\hline Item & EoED & EoTD & EoHF \\
\hline$\dot{E}_{\text {diss }}(\mathrm{W} \mathrm{K})$ & 14088025 & 14109068 & 17947828 \\
$\dot{m}_{\mathrm{c}}(\mathrm{kg} / \mathrm{s})$ & 1.83 & 2.01 & 2.49 \\
$\varepsilon$ & 0.63 & 0.60 & 0.56 \\
$E^{*}$ & 0.39 & 0.40 & 0.48 \\
\hline
\end{tabular}

minimize the entransy dissipation. As mentioned above, the difference between the results obtained using the EoED principle and the EoTD principle is very small. For the sake of simplicity, the EoTD principle is selected to qualitatively optimize the two-fluid heat exchanger. Regardless of the fouling resistance, the total heat transfer coefficient can be written as

$$
U=\left(\frac{1}{K_{\mathrm{h}}}+\frac{1}{K_{\mathrm{c}}}\right)^{-1},
$$

where, $K_{\mathrm{h}}$ and $K_{\mathrm{c}}$ are the heat transfer coefficients on the hot fluid side and cold fluid side. When the dimensions of the heat exchanger remain the same, according to the D-B correlation, the heat transfer coefficient can approximately be expressed as [21]:

$$
\begin{gathered}
K_{\text {new }}=K_{\text {old }}\left(\frac{\dot{m}_{\text {new }}}{\dot{m}_{\text {old }}}\right)^{0.8}, \\
U_{\text {new }}=\left(\frac{1}{K_{\text {new }}}+\frac{1}{K_{\text {the other }}}\right)^{-1} .
\end{gathered}
$$

Assume the heat transfer coefficients on the hot fluid side and cold fluid side are $K_{\mathrm{h}}=900 \mathrm{~W} \mathrm{~m}^{-2} \mathrm{~K}^{-1}$ and $K_{\mathrm{c}}=800 \mathrm{~W} \mathrm{~m}^{-2} \mathrm{~K}^{-1}$, and the parameters on one side are variable while the parameters on the other side remain the same throughout the optimization process. Under a given heat duty and heat transfer area, the two-fluid heat exchangers are optimized using the EoTD principle, and the optimization results are shown in Table 2. In Table 2, the subscripts $i$ and o denote inlet and outlet, and $A$ represents the heat transfer area.

From Table 2, it can be seen that it is not always possible to obtain better performance after optimization, and choosing an inappropriate fluid may lead to worse results. After observing Table 2 carefully, it can be found that the case which increases the mass flow rate after optimization will reduce the total entransy dissipation, or the case which increases the total heat transfer coefficient after optimization will lead to a reduction of the total entransy dissipation. To further observe the variation in the temperature in the optimization, the temperature profiles of the hot and cold fluids along the heat exchanger before and after optimization are shown in Figures 3 and 4. Figure 3 shows the temperature profiles of the hot and cold fluids in the heat exchanger before and after optimization, when the appropriate fluid is chosen. As shown in Figure 5, the temperature profiles of the hot and cold fluids along the heat exchanger are parallel after optimization, which is consistent with the EoTD principle. Both temperature profiles are closer to each other after optimization than before optimization, indicating that the temperature difference between the hot and cold fluids is reduced after optimization. Figure 4 shows the temperature profiles of the hot and cold fluids along the heat exchanger before and after optimization, when an inappropriate fluid is chosen. As shown in Figure 4, the temperature 

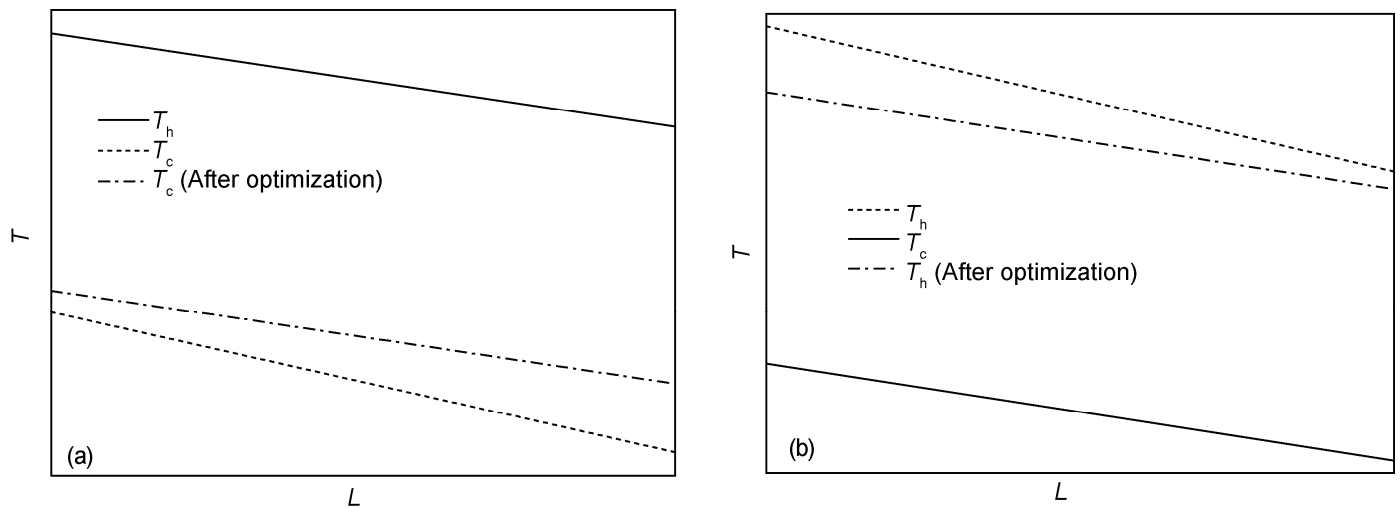

Figure 3 Temperature profiles of both fluids before and after optimization when the proper choice is (a) cold fluid and (b) hot fluid.
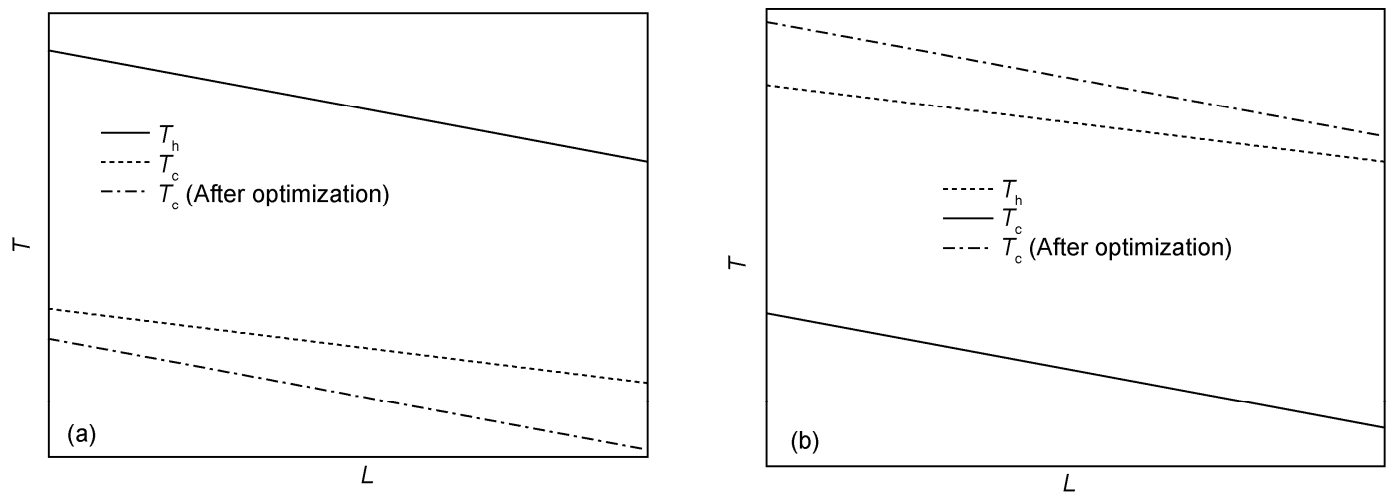

Figure 4 Temperature profiles of both fluids before and after optimization when the improper choice is (a) cold fluid and (b) hot fluid.

Table 2 Optimization results obtained using the EoTD principle in different cases

\begin{tabular}{|c|c|c|c|c|c|c|c|c|c|}
\hline & $T_{\mathrm{h}, \mathrm{i}}(\mathrm{K})$ & $T_{\mathrm{h}, \mathrm{o}}(\mathrm{K})$ & $T_{\mathrm{c}, \mathrm{i}}(\mathrm{K})$ & $T_{\mathrm{c}, \mathrm{o}}(\mathrm{K})$ & $\dot{m}_{\mathrm{h}}(\mathrm{kg} / \mathrm{s})$ & $\dot{m}_{\mathrm{c}}(\mathrm{kg} / \mathrm{s})$ & $A\left(\mathrm{~m}^{2}\right)$ & $U\left(\mathrm{~W} \mathrm{~m}^{-2} \mathrm{~K}^{-1}\right)$ & $\dot{E}_{\text {diss }}(\mathrm{W} \mathrm{K})$ \\
\hline \multicolumn{10}{|l|}{ Case 1} \\
\hline Before & 370 & 360 & 300 & 320 & 2 & 1 & 3.60 & 423.53 & 4599870 \\
\hline Cold fluid & 370 & 360 & 317.51 & 327.51 & 2 & 2 & 3.60 & 546.73 & 3553477 \\
\hline $\begin{array}{c}\text { Hot fluid } \\
\text { Case } 2\end{array}$ & 393.98 & 373.98 & 300 & 320 & 1 & 1 & 3.60 & 314.02 & 6186964 \\
\hline Before & 370 & 350 & 300 & 310 & 1 & 2 & 3.60 & 423.53 & 4599870 \\
\hline Cold fluid & 370 & 350 & 273.63 & 293.63 & 1 & 1 & 3.60 & 304.18 & 6386939 \\
\hline $\begin{array}{l}\text { Hot fluid } \\
\text { Case } 3\end{array}$ & 353.86 & 343.86 & 300 & 310 & 2 & 2 & 3.60 & 529.61 & 3668331 \\
\hline Before & 370 & 350 & 280 & 310 & 3 & 2 & 9.13 & 423.53 & 16308630 \\
\hline Cold fluid & 370 & 350 & 294.64 & 314.64 & 3 & 3 & 9.13 & 496.32 & 13889366 \\
\hline $\begin{array}{c}\text { Hot fluid } \\
\text { Case } 4\end{array}$ & 386.57 & 356.57 & 280 & 310 & 2 & 2 & 9.1 & 358.83 & 19211227 \\
\hline Before & 370 & 340 & 280 & 300 & 2 & 3 & 9.13 & 423.53 & 16308630 \\
\hline Cold fluid & 370 & 340 & 261.97 & 291.97 & 2 & 2 & 9.13 & 352.11 & 19578070 \\
\hline Hot fluid & 356.41 & 336.41 & 280 & 300 & 3 & 3 & 9.13 & 487.02 & 1415197 \\
\hline
\end{tabular}

profiles of the hot and cold fluids along the heat exchanger are more parallel after optimization, which satisfies the EoTD principle, but the total entransy dissipation rate is not reduced after optimization as shown in Table 2. From Figure 4 , one can see that the temperature profiles of the hot and cold fluids are farther apart after optimization, which means that the temperature difference between the hot and cold fluids increases. Contrasting Figure 3 with Figure 4, one can see that when the temperature profiles of the hot and cold fluids only meet the EoTD principle after optimization, the total entransy dissipation rate may not be reduced. Only when the temperature profiles of the hot and cold fluids are parallel and the temperature difference between the hot and cold fluids lowers simultaneously after 
optimization, can the total entransy dissipation rate decrease. Therefore, the proper choice between the two alternative fluids has an important role in the successful application of the entransy dissipation minimization principles.

\section{Conclusions}

For a given heat duty and heat transfer area, the comparison of the results obtained using the EoED, EoTD and EoHF principles, illustrates that when the heat transfer coefficient is variable the EoED principle has the best performance, followed by the EoTD principle and then the EoHF principle. The difference between the results obtained using the EoED and EoTD principles is very small, far smaller than that between the results obtained using the EoED and EoHF principles. In practice, for the sake of the simplicity, the EoTD principle could take the place of the EoED principle to minimize entransy dissipation.

Given the heat duty and heat transfer area, the results of the applications of the EoTD principle to different fluids in two-fluid heat exchanger show that improper choice of the two alternative fluids may lead to a worse performance in terms of entransy dissipation after optimization. Therefore, choosing the proper fluid has an important role in the successful application of the entransy dissipation minimization principles. Between the two alternative fluids, a choice that increases the total heat transfer coefficient, or makes the temperature profiles of the hot and cold fluids parallel and lessens the temperature difference between the hot and cold fluids simultaneously, is the proper one.

This work was supported by the National Natural Science Foundation of China (50876054).

1 Yilmaz M, Sara O N, Karsli S. Performance evaluation criteria for heat exchangers based on second law analysis. Exergy Int J, 2001, 1: 78-294

2 Prigogine I. Introduction to Thermodynamics of Irreversible Processes. 3rd. New York: Wiley, 1967. 76-77

3 Bejan A. Entropy Generation through Heat and Fluid Flow. New York: Wiley, 1982. 118-134
4 Bejan A. Entropy Generation Minimization. Boca Raton: CRC Press, 1996. 47-112

5 Tondeur D, Kvaalen E. Equipartition of entropy production: An optimality criterion for transfer and separation process. Ind Eng Chem Res, 1987, 26: 50-56

6 Sauar E, Ratkje S K, Lien K M. Equipartition of forces: A new principle for process design and optimization. Ind Eng Chem Res, 1996, 35: 4147-4153

7 Balkan F. Comparison of entropy minimization principles in heat exchange and a short-cut principle: EoTD. Int J Energy Res, 2003, 27: 1003-1014

8 Guo Z Y, Li Z X, Zhou S Q, et al. Principle of uniformity of temperature difference field in heat exchanger. Sci China Ser E-Tech Sci, 1996, 39: 68-75

9 Bertola V, Cafaro E. A critical analysis of the minimum entropy production theorem and its application to heat and fluid flow. Int $\mathrm{J}$ Heat Mass Transfer, 2008, 51: 1907-1912

10 Bejan A. Second law analysis in heat transfer. Energy, 1980, 5: 721762

11 Hesselgreaves J E. Rationalisation of second law analysis of heat exchangers. Int J Heat Mass Transfer, 2000, 43: 4189-4204

12 Guo Z Y, Cheng X G, Xia Z Z. Least dissipation principle of heat transport potential and its application in heat conduction optimization. Chinese Sci Bull, 2003, 48: 406-410

13 Guo Z Y, Zhu H Y, Liang X G. Entransy - A physical quantity describing heat transfer ability. Int J Heat Mass Transfer, 2007, 50: 2545-2556

14 Han G Z, Guo Z Y. Physical mechanism of heat conduction ability dissipation and its analytical expression (in Chinese). Proc CSEE, 2007, 27: 98-102

15 Xu M T, Guo J F, Cheng L. The application of entransy dissipation theory in heat convection. Front Energy Power Eng China, 2009, 3: 402-405

16 Liu X B, Meng J A, Guo Z Y. Entropy generation extremum and entransy dissipation extremum for heat exchanger optimization. Chinese Sci Bull, 2009, 54: 943-947

17 Song W M, Meng J A, Liang X G, et al. Demonstration of uniformity principle of temperature difference field for one-dimensional heat exchangers. J Chem Indust Engin (China), 2008, 59: 2461-2464

18 Xia S J, Chen L G, Sun F R. Optimization for entransy dissipation minimization in heat exchanger. Chinese Sci Bull, 2009, 54: 35873595

19 Guo J F, Xu M T, Cheng L. Principle of equipartition of entransy dissipation for heat exchanger design. Sci China Tech Sci, 2010, 53: 1309-1314

20 Guo J F, Cheng L, Xu M T. Entransy dissipation number and its application to heat exchanger performance evaluation. Chinese Sci Bull, 2009, 54: 2708-2713

21 Balkan F. Application of EoEP principle with variable heat transfer coefficient in minimizing entropy production in heat exchangers. Energy Convers Manage, 2005, 46: 2134-2144

Open Access This article is distributed under the terms of the Creative Commons Attribution License which permits any use, distribution, and reproduction in any medium, provided the original author(s) and source are credited. 